\title{
Nutrition and Behaviour Group Symposium on 'Measuring nutrient intake' Measuring food intake in farm and laboratory animals
}

\author{
Bert J. Tolkamp ${ }^{1 *}$, Jon E. L. Day ${ }^{2}$ and Ilias Kyriazakis ${ }^{1}$ \\ ${ }^{1}$ Animal Biology Division, Scottish Agricultural College, Bush Estate, Penicuik, Midlothian EH16 OPH, UK \\ ${ }^{2}$ Consumer Sciences Department, Institute of Food Research, Reading, UK
}

Measurement of food intake in farm and laboratory animals is often relatively easy compared with that of animals and human subjects that are free living, as will be evident from the subsequent papers in the present symposium. There are, however, some circumstances in which intake measurements of farm or laboratory animals still present methodological problems. The first aim of the present paper is to review briefly these problem areas and give recent references that provide a more in-depth discussion of the methodologies concerned.

When measuring food intake of farm and laboratory animals we generally have control over the animals as well as the feeds and the environmental conditions. This facilitates the measurement of daily nutrient intake of individual animals with great accuracy. In addition, more and more detailed information on feeding behaviour for much shorter time scales becomes available through the use of automated measuring equipment (for example, see for pigs: Young \& Lawrence, 1994; for rats: Madrid et al. 1995; for cows: Tolkamp \& Kyriazakis, 1997). A great challenge is the interpretation of the variation in food intake and of feeding behaviour. The present contribution also aims to highlight one of the problems regarding this issue; the relevant time scale for measurement of food intake and its interpretation.

In view of our research backgrounds, we hope to achieve this aim by using data from scientific fields that sometimes seem to have developed quite separately. The first field relates to food intake measurements with laboratory animals. The aim of experiments with laboratory animals is generally a better understanding of food intake regulation in mature mammals, with particular emphasis on possible applications to man. The second field relates to food intake and feeding behaviour measurements of mainly growing or reproducing farm animals. A major proportion of this type of data exists because of the economic importance of food intake in animal farming systems. Some of these data result from research aimed at finding solutions to practical problems. However, other data also refer to experiments specifically carried out to test hypotheses with regard to food intake regulation. Thus, these results may also be very useful, not least because of the detail in which nutrient intake and utilization is frequently recorded in farm animals.

We will first highlight the apparent flexibility with which farm and laboratory animals adjust their short-term feeding behaviour without compromising their desired food intake level. This raises the question of what it is that animals try to achieve, and on what time scale they attempt to do this, i.e. the search for a functional explanation of feeding behaviour. This approach seems especially relevant in reaching a better understanding of the animal's responses to changes in its food and in its environment, and in arriving at improved predictions of food intake.

\section{Methodological problems when measuring food intake}

The usual method of measuring voluntary food intake is by difference, i.e. by weighing the food before, and again after, consumption has occurred. If foods are homogeneous and if sufficient care is taken to avoid spillage, accurate measurements of the intake of food, energy and nutrients can be obtained by this method. Problems may arise if the quantity of food cannot be weighed very accurately before and after consumption has occurred (as in sucking or grazing animals) or if food is heterogeneous and allows selection (especially for the foods offered to herbivores). In addition, there are methodological problems associated with measurements of food intake as part of studies investigating other behaviours.

\section{Measuring intake of sucking animals}

The technique most generally applied involves weighing of the young before and after sucking ('weigh-suckleweigh'). Young that are kept separated from their dam are allowed access to the dam during one or more short period(s) during the day and/or night, depending on the 
natural frequency of suckling (for example, see Davies $e t$ al. 1964; Campbell \& Dunkin, 1982; Adenuga et al. 1991; King et al. 1997; Spinka et al. 1997). The young are weighed carefully immediately before and immediately after access to the dam. If suckling periods are short, weight losses through lungs and skin are so small that these can be ignored. All accurate weighings (excluding those where voidance of dung or urine occurred during suckling) can then be used to calculate average daily milk intake of the young.

Two alternatives to the direct weigh-suckle-weigh technique have been used. The most frequently used involves artificial milking of the dam before feeding the milk to the young animal, with (for example, see Akinbamijo et al. 1994; Bencini, 1995; Purroy \& Jaime, 1995), or without, the help of oxytocin injection to stimulate milk let-down (for example, see Delongeas $e t$ al. 1997). A benefit of this technique is that it allows analyses of milk composition. However, it is also associated with a number of problems. It has been reported that artificial milking can result in overestimates as well as underestimates of normal intake by the young (for discussion, see Aboul-Naga et al. 1981; Akinbamijo et al. 1995). As milk composition is not constant during milking, errors may also occur in estimating milk composition (for example, see Bencini, 1995).

A more recent technique is the use of ${ }^{3} \mathrm{H}$, mostly in the form of ${ }^{3} \mathrm{H}_{2} \mathrm{O}$, to estimate transfer of milk from dam to young (for example, see Lydersen et al. 1992; Ternouth \& Budhi, 1996; Monaco \& Donvan, 1997). The technique relies on determination of ${ }^{3} \mathrm{H}$ concentrations in body fluids. It is evident that the reliability of this technique depends on the accuracy of the model that is used to describe the behaviour of the different ${ }^{3} \mathrm{H}$ pools in the dam as well as the young, and the technique can only be applied when these models are available (for discussion, see Edlund, 1995).

At present, therefore, the most reliable method to estimate intake of sucking young seems to be the weighing of young before and after suckling. If energy and/or nutrient intake and, therefore, milk composition has to be measured, this can be combined with artificial milking.

\section{Measuring intake of heterogeneous foods}

In certain types of experimental work heterogeneous foods are fed, for example in forage evaluation studies with herbivores (for example, see Zemmelink, 1980, 1986; Wahed et al. 1990; Bosman et al. 1995). In such studies, voluntary intake and nutritive value (e.g. digestibility and protein content) of the consumed food is of great importance. To obtain accurate estimates, forage is frequently harvested and fed to animals indoors. For the measurement of voluntary intake of forages, it is generally recommended to offer a daily amount of food which is equal to $110-115 \%$ of daily intake (for example, see Blaxter et al. 1961; Minson, 1990). However, both food intake and the composition of the food consumed can be affected very strongly by the amount offered if foods are heterogeneous. Heterogeneity can refer to different plant parts of the same species (for instance, leaves and stems; for example, see Zemmelink, 1980, 1986; Wahed et al. 1990) or even to different plant species (for example, see Bosman et al. 1995). Heterogeneity gives experimental animals opportunities to select. These opportunities increase as the amount of food offered increases. The result is that when more food is offered than the recommended 110 $115 \%$ of daily intake, animals generally eat more food that is of a higher quality. How much more food is consumed as a result of increased amounts offered varies, depending to a large extent on the morphological characteristics of the plants fed. Zemmelink $(1980,1986)$ has provided an elegant model to describe the effects of amounts of heterogeneous food offered on voluntary food intake and composition of food consumed. This model has a number of advantages over other models used in the literature (for discussion, see Zemmelink, 1986; Bosman et al. 1995). From this and other work (for example, see Wahed et al. 1990; Rao et al. 1994; Bitende \& Ledin, 1996), it is evident that the evaluation of food quality, as well as that of animal performance, by food intake measurements of heterogeneous foods depends to a large extent on the amounts of food offered. The nature of the problem does not allow standardization of experimental procedures to one level of refusal. To obtain good estimates, voluntary food intake has to be measured at a series of levels. Depending on the research question, food quality and expected animal performance can then be evaluated with techniques such as those described by Zemmelink (1986) and those used by Bosman et al. (1995).

\section{Measuring intake of grazing farm animals}

The problems associated with measuring intake in grazing farm animals are essentially the same as the problems associated with intake measurements of animals in the wild (see Chivers (1998) in the present symposium) and falls outside the scope of the present paper. A useful general overview of existing techniques and associated problems is provided by Gordon (1995). A detailed account of one of the promising recently-developed techniques, using nalkanes, is given by Hatt et al. (1997).

\section{Measuring food intake as part of investigations related to other behaviours}

Measurements of food intake are also essential for the study of learning in modern experimental psychology. In these studies, food is often used as a reward (reinforcer) as it is generally very effective. The study of animal learning has produced many experimental paradigms involving food reinforcement. The use of salivation by Pavlov (1927) to demonstrate classical conditioning is well known. Food reinforcement was also used by Skinner (1938) to demonstrate instrumental, or operant, conditioning, which is a type of associative learning where a behaviour, such as pressing a lever (the operant behaviour), becomes associated with a reinforcing stimulus, e.g. the presentation of food. This paradigm has been used widely by psychologists to study instrumental learning because a diverse range of contingencies between operant behaviour and reinforce- 
ment can be arranged (for review, see Ferster \& Skinner, 1957). The methodology has also been used by applied ethologists to study the levels of motivation in domestic animals (for review, see Day et al. 1997). Measurements of voluntary food intake are an integral part of all these studies.

Whilst great advances in our understanding of classical and instrumental conditioning have been made through the use of these paradigms, there are experimental dangers associated with the use of food as a reinforcer. In the highly-controlled conditions necessary to test hypotheses concerning learning, there are many confounding factors which can reduce the validity of experiments. These confounding factors can be grouped into those concerning the experimental animals themselves, and those concerning experimental design.

Animal factors. The choice of animal species used in a learning experiment is often made on the basis of convenience (Mackintosh, 1974). However, there is an increasing realization that there are tangible differences in learning processes both between and within species. For example, species such as the rat and the pig both show a bimodal distribution of feeding activity, but differ markedly because rats feed predominantly in the dark and pigs feed predominantly in the light period (rats: Kersten et al. 1980; pigs: De Haer \& Merks, 1992). Furthermore, many species show annual rhythms, such as the deposition of body fat reserves and breeding cycles, both of which directly affect food intake and diet selection.

Voluntary food intake of animals is known to be affected by their nutritional history, body condition, sex, breed and age (see Kyriazakis, 1994). Most experiments, therefore, use a sample of animals with homogeneous sex, breed and age, and reject individuals with poor body condition. However, nutritional history can have quite a marked effect on food intake and is often difficult to quantify and to control. Level of feeding motivation is affected by the previous nutritional status, which affects subsequent learned associations (Mackintosh, 1974); 'A Joule to a starving animal is more of a jewel than a Joule to a satiated animal.' (Caraco et al. 1990). This is supported by experimental evidence that animals will form stronger food flavour preferences when motivated to feed than when satiated (rats: Capaldi et al. 1994; pigs: Day et al. 1996a), and that animals motivated to feed will express operant behaviour at a higher rate than satiated animals (rats: Clark, 1958; Carlton, 1961; pigeons: Ferster \& Skinner, 1957; pigs: Day et al. 1996b). Thus, the effects of previous periods of undernutrition or malnutrition need to be considered.

Experimental factors. In many experiments studying animal behaviour, food intake measurements are interpreted without any reference to the nutritional value of the food (see Fantino \& Abarca, 1985) despite the fact that food is more than just an energy source. Animals require specific macro- and micronutrients for maintenance, growth and reproduction, and it has been shown that voluntary energy intake can vary considerably depending on the concentration of nutrients, e.g. protein (for example, see Kyriazakis, 1994). Thus, the composition of the food needs to be considered and described.
Another factor which has to be considered when food is used as a reinforcer is whether food intake is measured in an open or closed economy. In an open-economy experiment the animal can obtain food and water within, as well as outside, the testing situation; in a closed-economy experiment the animal obtains its entire food intake within the testing situation (Killeen, 1995). If an animal is required to pay for food in an instrumental conditioning paradigm by pressing a lever, the value of food to that animal can be ascertained by increasing its cost in terms of work. The food is considered to have a demand function which is more or less elastic, depending on the extent to which the animal is prepared to work to obtain the food. Economic theories, from whence these behavioural analogies derive, propose that demand functions that have low elasticity reflect items which are viewed as necessities. Demand functions of high elasticity reflect items which are viewed as luxuries. In accordance with this paradigm, Hursh (1980) showed that monkeys showed an inelastic demand for food in a closed economy, but an elastic demand for the same food in an open economy.

\section{What are relevant time scales for animal feeding behaviour?}

\section{Meal patterns and food intake regulation}

Food is consumed in discrete meals, in laboratory as well as farm animals. Average daily intake is, of course, the result of the meal pattern (i.e. the average number of daily meals multiplied by the average size of these meals). Scientists investigating the mechanisms of daily food intake regulation have turned their attention, therefore, to meal patterns as a possible explanation for variation in intake. It has been shown that variation in meal patterns can be associated with variation in intake under certain conditions (for example, see Collier \& Johnson, 1990; Elizalde \& Mayne, 1993). Clearly, under such experimental conditions, meal patterns seem to determine total daily food intake. However, there is ample evidence that under a wide array of experimental conditions meal patterns may show considerable variation within, as well as between, animals without any relation to food intake or animal performance. Fig. 1 illustrates this

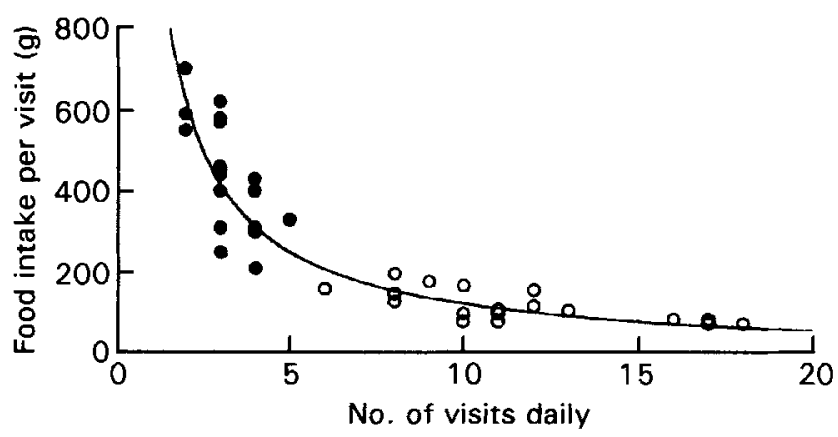

Fig. 1. Daily number of meals and meal size for two pigs of similar genotype at a similar physiological stage on the same food during $21 \mathrm{~d}$. The solid line indicates the combination of daily meal number and average meal size resulting in a daily food intake of $1260 \mathrm{~g}$, the mean daily intake during this period of both pigs. (From Nielsen, 1995.) 
Table 1. Meal patterns, food intake and performance of pigs of similar genotype at similar physiological stages and on the same food under two experimental conditions: one or four feeder space(s) per pig (From Nielsen et al. 1995)

\begin{tabular}{lccc}
\hline & $\begin{array}{c}\text { Four-space } \\
\text { feeder }\end{array}$ & $\begin{array}{c}\text { One-space } \\
\text { feeder }\end{array}$ & $\begin{array}{c}\text { Statistical } \\
\text { significance } \\
\text { of difference }\end{array}$ \\
\hline No. of daily visits & 85 & 14 & $* \star \star$ \\
Intake (g per visit) & 24 & 149 & $* * \star$ \\
Duration (min per visit) & $0-7$ & 4.7 & ${ }^{* \star *}$ \\
Daily food intake (g) & 1760 & 1766 & NS \\
Daily wt gain (g) & 810 & 813 & NS \\
\hline
\end{tabular}

$\star * * P<0.001$

point with data obtained from pigs in our laboratory (Nielsen, 1995).

The two pigs showed the same average daily food intake and weight gain, although one consumed many small meals, and the other a few large meals. In addition, there is abundant evidence that experimental conditions can have a profound effect on meal patterns without any appreciable effect on farm animal intake and performance. As an example, Table 1 gives some data, again collected with pigs (Nielsen et al. 1995). Animal performance (in terms of food intake and daily weight gain) was the same in both experimental designs. Experimental design had, however, a profound effect on meal patterns, with a smaller number of longer visits when only one feeding place was available compared with when four feeding places were available.

Similar examples are available for dairy cows (for example, see Harb et al. 1985; Elizalde \& Mayne, 1993), beef steers (for example, see Gonyou \& Stricklin, 1981; Corkum et al. 1994) and rats (for example, see Collier \& Johnson, 1990, 1997). Fig. 1 of Collier \& Johnson (1990) summarizes a study in which rats had to perform work (the pushing of levers) before gaining access to food; after gaining access, meal size was not restricted. The study shows that a rat offered access to a given food, can achieve the same average daily intake through fundamentally different meal patterns, depending on the experimental conditions. These data show that animals can react with a great deal of flexibility in their meal patterns in response to changing experimental conditions, while maintaining food intake constant. Of course, in a purely formal sense, average daily intake is, under all these conditions, still the result of the meal patterns (i.e. the product of the average number of meals and the average meal size). The data suggest, however, that under a wide array of conditions this reasoning can also be turned around; meal patterns are the result of, on the one hand, the animal's desire for a given average daily food intake level (i.e. the animal's goal when it regulates intake) and, on the other hand, the experimental conditions.

On purpose, we have added the word 'average' before daily intake in the previous discussion. The expression of food intake on a daily basis has, of course, some justification in that the dark-light cycle imposes a diurnal rhythm on the animals' behaviour. Numerous observations suggest, however, that the relevant 'time-window' for food intake regulation is longer than $1 \mathrm{~d}$ in large farm animals (e.g. pigs; as discussed by Lawrence \& Illius, 1997) as well as small laboratory species (e.g. rats; Collier \& Johnson, 1990). This raises the question of whether we can understand food intake regulation as an attempt by the animal to achieve very short-term goals (i.e. $1 \mathrm{~d}$ or shorter) or as the result of behavioural programmes aimed at longerterm goals.

\section{Functional explanations of feeding behaviour}

The behavioural programmes of animals as we know them today are the result of many generations of natural selection. In addition, farm and laboratory animals have been subject to artificial rather than natural selection for some generations. However, ethologists agree that artificial selection has generally left the essential details of behaviour unaffected (Brantas, 1978; but see also Kyriazakis, 1997). Thus, many farm and laboratory animals still largely possess the original organization and strategies which for so many generations contributed to fitness, i.e. survival, growth and reproduction (Wiepkema, 1992; Siegel, 1993).

In behavioural ecology, functional explanations of animal behaviour are rooted in the general belief that behavioural programmes have evolved on the basis of selective advantage in terms of fitness (for a general text, see Krebs \& Davies, 1987). In optimal foraging theory it is frequently assumed that for many species these long-term goals are best served by short-term rate-maximization behaviour, i.e. animal feeding behaviour is modelled as if it were aimed at maximizing food intake per unit time (for an overview, see Stephens \& Krebs, 1986). With some exceptions (for example, see Emmans \& Kyriazakis, 1995; Ketelaars \& Tolkamp, 1996; Emmans, 1997) this is also the dominant view in the farm animal literature, even when this assumption is frequently implicit and not discussed at all. For example, Poppi et al. (1994) discuss several mechanisms that are assumed to limit intake without even mentioning the underlying assumption that animals are intake-rate maximizers. In the farm animal literature in general there is a similar emphasis on causal, as opposed to functional, explanations.

In contrast with the farm animal literature which deals largely with growing and reproducing animals, the laboratory animal literature is dominated by research involving mature, non-reproducing rats. The point of view of LeMagnen (1985) seems to be representative of the concept that has dominated the laboratory animal literature for decades (for discussion, see Collier \& Johnson, 1997). This concept assumes that animals try to regulate their food intake as a relatively simple, very short-term, depletionrepletion model, i.e. animals try to maintain their body weight and body reserves by adding exactly the amount of energy that is expended. Also in the laboratory animal literature there is a strong emphasis on mechanistic explanations of variation in food intake. This shows that the emphasis in the laboratory and farm animal literature is different, probably as a result of the types of animal that are under study (mature $v$. growing or reproducing). The dominant view in both, however, is that animals try to 
achieve short-term goals and the emphasis in the research efforts is aimed at mechanistic explanations of short-term variation in food intake. This contrasts sharply with the emphasis on long-term strategies and functional explanations in behavioural ecology. As Collier \& Johnson (1990) have pointed out for laboratory animals, this focus on mechanisms while ignoring questions about function has limited attention to a time-window that is much narrower than the time span that is relevant for survival, growth and reproduction. Similarly, we have argued in favour of considering short-term feeding behaviour of farm animals as part of a longer time-window (Tolkamp \& Ketelaars, 1992; Emmans \& Kyriazakis, 1995; Ketelaars \& Tolkamp, 1996; Kyriazakis, 1997). At present, the mechanisms involved in the long-term regulation of feeding behaviour are largely unknown (Collier \& Johnson, 1990) or at best speculative (see Tolkamp \& Ketelaars, 1992 as discussed by Emmans \& Kyriazakis, 1995; also Ketelaars \& Tolkamp, 1996; Emmans, 1997). The search for the longterm mechanisms of feeding behaviour, however, cannot be solved without raising the question as to its goal. We believe that a collaboration between scientists interested in the 'why' of food intake regulation and those interested in the 'how' will prove to be particularly fruitful.

\section{Conclusions}

Apart from some special conditions that have been discussed, the accurate measurement of average daily food intake of farm and laboratory animals does not present great problems. The time scale considered relevant for the interpretation of daily food intake measurements depends largely on the outlook of the scientist. Ecologists may be primarily interested in functional explanations, i.e. what are the benefits and what are the costs of different food intake behavioural programmes in relation to long-term fitness. From this point of view, average daily intake can be considered as a short-term part of a longer-term feeding strategy. In contrast, those scientists interested in the mechanisms of food intake regulation tend to consider daily intake as the result of shorter-term events; i.e. meal patterns.

The dominant view in the laboratory animal literature, based mainly on observations of adult animals, seems to be that animals have a very short 'time-window' and behave according to a depletion-repletion model. In animal science, where work is mainly with young and growing or reproducing animals, the dominant (and frequently implicit) view is that animals are short-term intake ratemaximizers subject to constraints, and much of the research effort is aimed at elucidating these constraints. In our experience, the approach of looking for mechanistic explanations is poorly connected with the approach searching for functional explanations. Indeed, with some exceptions, mechanisms in animal science are discussed with implicit assumptions about the animal's aim. Similarly, in a substantial part of the rat literature one axiom with regard to the animal's goal is dominant ('homeostasis') and hardly the subject of critical debate. Attempts to elucidate the mechanisms of food intake regulation can only benefit from critical reflection on possible functional explanations of food-intake behaviour programmes. If these programmes evolved because they brought benefits to genotypes equipped with them, these programmes must have contributed to longer-term survival and fitness. A disproportionate emphasis on short-term effects seems, therefore, unwarranted and to lead to limited research achievements. At present, the mechanisms involved in longer-term regulation remain largely unknown. A closer collaboration between scientists with a primary interest in functional explanations and those with a primary interest in mechanistic explanations is required to improve our understanding of the food intake responses of animals to changing conditions.

\section{References}

Aboul-Naga AM, El-Shoboksh AS \& Moustafa MA (1981) Milk production from sub-tropical non-dairy sheep 2. Method of measuring. Journal of Agricultural Science, Cambridge 79 , 303-308.

Adenuga MK, Tolkamp BJ, Ademosun AA, Montsma G \& Brouwer BO (1991) Effect of pregnancy and lactation on liveweight, feed intake and feeding behavior in West African Dwarf (WAD) goats. Small Ruminant Research 4, 245255.

Akinbamijo OO, Reynolds L, Sherington J \& Nsahlai IV (1994) Effect of post-partum Trypanosoma vivax infection on feed intake, live weight changes, milk yield and composition, in West-African Dwarf ewes and associated lamb growth rate. Journal of Agricultural Science, Cambridge 123, 387-392.

Bencini R (1995) The use of intramuscular oxytocin injections to measure milk output in nondairy sheep and its effect on milk composition. Australian Journal of Experimental Agriculture 35, 563-565.

Bitende SN \& Ledin I (1996) Effect of doubling the amount of low quality grass hay offered and supplementation with Acacia tortilis fruits or Sesbania sesban leaves on intake and digestibility by sheep in Tanzania. Livestock Production Science 45, 39-48.

Blaxter KL, Wainman FW \& Wilson RS (1961) The regulation of feed intake by sheep. Animal Production 3, 51-62.

Bosman HG, Versteegden CJGM, Odeyinka SM \& Tolkamp BJ (1995) Effect of amount offered on intake, digestibility and value of Gliricidia sepium and Leucaena leucocephala for West African Dwarf goats. Small Ruminant Research 15, 247-256.

Brantas GC (1978) Loss of variation in the behaviour of animals. Proceedings of the Zodiac Symposium on Adaptation, Wageningen, pp. 32-35. Wageningen, The Netherlands: Centre for Agricultural Publishing and Documentation.

Campbell RG \& Dunkin AC (1982) The effect of birth weight on the estimated milk intake, growth and body composition of sow-reared piglets. Animal Production 35, 193-197.

Capaldi ED, Owens J \& Palmer KA (1994) Effects of food deprivation on learning and expression of flavor preferences conditioned by saccharin or sucrose. Animal Learning and Behavior 22, 173-180.

Caraco T, Blanckenhorn WU, Gregory GN, Newman JA, Recer GM \& Zwicker SM (1990) Risk-sensitivity: ambient temperature affects foraging choice. Animal Behaviour 39, 338-345.

Carlton PL (1961) The interacting effects of deprivation and reinforcement. Journal of the Experimental Analysis of Behavior 4, 379-381.

Clark FC (1958) The effect of deprivation and frequency of reinforcement on variable-interval responding. Journal of the Experimental Analysis of Behavior 1, 221-227. 
Chivers DJ (1998) Measuring food intake in wild animals: primates. Proceedings of the Nutrition Society 57, 321-332.

Collier G \& Johnson DF (1990) The time window of feeding. Physiology and Behavior 48, 771-777.

Collier G \& Johnson DF (1997) Who is in charge? Animal vs. experimenter control. Appetite 29, 159-180.

Corkum MJ, Bate LA, Tennessen T \& Lirette A (1994) Consequences of reduction of number of feeders on feeding behaviour and stress level of feedlot steers. Applied Animal Behaviour Science 41, 27-35.

Davies JS, Widdowson EM \& McCance RA (1964) The intake of milk and the retention of its constituents while the newborn rabbit doubles its weight. British Journal of Nutrition 18, 385392.

Day JEL, Kyriazakis 1 \& Lawrence AB (1996a) An investigation into the causation of chewing behaviour in the growing pig: the effect of exploration and feeding motivation. Applied Animal Behaviour Science 48, 47-59.

Day JEL, Kyriazakis I \& Lawrence AB (1996b) The use of a second-order schedule to assess the effect of food bulk on the feeding motivation of growing pigs. Animal Science 63, 447455.

Day JEL, Kyriazakis I \& Rogers PJ (1997) Feeding motivation in animals and humans: a comparative review of its uses and measurement. Nutrition Abstracts and Reviews 66A, 107117.

De Haer LC \& Merks JWM (1992) Patterns of daily food intake in growing pigs. Animal Production 54, 95-104.

Delongeas JL, Trabarel C \& Guittin P (1997) Easy procedure for milk collection in lactating rats. Contemporary Topics in Laboratory Animal Science 36, 80-83.

Edlund O (1995) COWTRI-a dynamic compartment model for the transfer of tritium to milk in a lactating dairy cow. Fusion Technology 28, 846-852.

Elizalde HF \& Mayne CS (1993) The effect of degree of competition per feed space on the dry matter intake and eating behaviour of dairy cows offered grass silage. In Proceedings of the Third Research Conference of the British Grassland Society, pp. 137-138. Antrim, Co. Antrim: British Grassland Society.

Emmans GC (1997) A method to predict the intake of domestic animals from birth to maturity as a function of time. Journal of Theoretical Biology 186, 189-199.

Emmans GC \& Kyriazakis I (1995) The idea of optimisation in animals: uses and dangers. Livestock Production Science 44, 189-197.

Fantino E \& Abarca N (1985) Choice, optimal foraging, and the delay-reduction hypothesis. Behavioral and Brain Sciences $\mathbf{8}$, 315-330.

Ferster CB \& Skinner BF (1957) Schedules of Reinforcement. New York: Appleton-Century-Crofts.

Gonyou HW \& Stricklin WR (1981) Eating behaviour of beef cattle groups, fed from a single stall or trough. Applied Animal Ethology 7, 123-133.

Gordon IJ (1995) Animal based techniques for grazing ecology research. Small Ruminant Research 16, 203-214.

Harb MY, Reynolds VS \& Campling RC (1985) Eating behaviour, social dominance and voluntary intake of silage in group-fed milking cattle. Grass and Forage Science 40, 113-118.

Hatt J-M, Mayes RW \& Lechner-Doll M (1997) Use of $n$-alkanes as markers for the study of digestive strategies in captive giraffes (Giraffa camelopardalis). Proceedings of the Nutrition Society 56, 323A.

Hursh SR (1980) Economic concepts for the analysis of behavior. Journal of the Experimental Analysis of Behavior 34, 219-238.
Kersten A, Strubbe JH \& Spiteri NJ (1980) Meal patterning of rats with changes in day length and food availability. Physiology and Behavior 25, 953-958.

Ketelaars JJMH \& Tolkamp BJ (1996) Oxygen efficiency and the control of energy flow in animals and humans. Journal of Animal Science 74, 3036-3051.

Killeen PR (1995) Economics, ecologics, and mechanics: the dynamics of responding under conditions of varying motivation. Journal of the Experimental Analysis of Behavior 64, 405-431.

King RH, Mullan BP, Dunshea FR \& Dove H (1997) The influence of piglet body weight on milk production of sows. Livestock Production Science 47, 169-174.

Krebs JR \& Davies NB (1987) An Introduction to Behavioural Ecology. Oxford: Blackwell Scientific Publications.

Kyriazakis I (1994) The voluntary food intake and diet selection of pigs. In Principles of Pig Science, pp. 85-105 [DJA Cole, J Wiseman and M Varley, editors]. Nottingham: Nottingham University Press.

Kyriazakis I (1997) Nutritional choices in farm animals: to eat or what to eat? In Animal Choices. Occasional Publication of the British Society of Animal Science no. 20, pp. 55-65 [JM Forbes, TLJ Lawrence, RG Rodway, MA Varley, $\mathbf{H}$ Davies and $\mathrm{C}$ Wooliams, editors]. Edinburgh: BSAS.

Lawrence AB \& Illius AW (1997) Measuring preferences and the problem of identifying proximate needs. In Animal Choices. Occasional Publication of the British Society of Animal Science no. 20, pp. 19-26 [JM Forbes, TLJ Lawrence, RG Rodway, MA Varley, H Davies and C Wooliams, editors]. Edinburgh: BSAS.

LeMagnen J (1985) Hunger. Cambridge: Cambridge University Press.

Lydersen C, Hammill MO \& Ryg MS (1992) The water flux and mass gain during lactation in free-living ringed seal (Phoca hispida) pups. Journal of Zoology 228, 361-369.

Mackintosh NJ (1974) The Psychology of Animal Learning. London: Academic Press.

Madrid JA, Matas P, Sanchez-Vazquez FJ \& Cuenca EM (1995) A contact eatometer for automated continuous recording of feeding behavior in rats. Physiology and Behavior 57, 129-134.

Minson J (1990) Forage in Ruminant Nutrition. San Diego, CA: Academic Press Inc.

Monaco MH \& Donvan SM (1997) Insulin-like growth factor-I infusion increases in vivo skeletal muscle and mammary alphaamino[1-C-14]isobutyric acid accumulation in food restricted lactating rats. Nutrition Research 17, 1143-1154.

Nielsen BL (1995) Feeding behaviour of growing pigs: effects of the social and physical environment. PhD Thesis, University of Edinburgh.

Nielsen BL, Lawrence AB \& Whittemore CT (1995) Effects of single-space feeder design on feeding behaviour and performance of growing pigs. Animal Science 61, 575-579.

Pavlov IP (1927) Conditioned Reflexes. Oxford: Oxford University Press.

Poppi DP, Gill M \& France J (1991) Integration of theories of intake regulation in growing ruminants. Journal of Theoretical Biology 167, 129-145.

Purroy A \& Jaime C (1995) The response of lactating and dry ewes to energy intake and protein source in the diet. Small Ruminant Research 17, 17-24.

Rao AS, Prabhu UH, Sampath SR \& Schiere JB (1994) The effect of level of allowance on the intake and digestibility of finger millet (Eleusine coracana) straw in crossbred heifers. Animal Feed Science and Technology 49, 37-41.

Siegel PB (1993) Behavior-genetic analysis and poultry husbandry. Poultry Science 72, 1-5.

Skinner BF (1938). The Behavior of Organisms. New York: Appleton-Century-Crofts. 
Spinka M, Illmann G, Algers B \& Stetkova Z (1997) The role of nursing frequency in milk production in domestic pigs. Journal of Animal Science 75, 1223-1228.

Stephens DW \& Krebs JR (1986) Foraging Theory. Princeton, NJ: Princeton University Press.

Ternouth JH \& Budhi SPS (1996) The effects of dietary phosphorus deficiency in pregnant and lactating ewes. Australian Journal of Experimental Agriculture 36, 137-144.

Tolkamp BJ \& Ketelaars JJMH (1992) Toward a new theory of feed intake regulation in ruminants. II. Costs and benefits of feed consumption: an optimization approach. Livestock Production Science 30, 297-317.

Tolkamp BJ \& Kyriazakis I (1997) Measuring diet selection in dairy cows: effects of training on choice of dietary protein level. Animal Science 64, 197-207.

Wahed RA, Owen E, Naate M \& Hosking BJ (1990) Feeding straw to small ruminants: effect of amount offered on intake and selection of barley straw by goats and sheep. Animal Production 51, 283-289.

Wiepkema PR (1992) On burdening of our livestock. Tijdschrift Diergeneeskunde 117, 141-145.

Young RJ \& Lawrence AB (1994) Feeding behaviour of pigs in groups monitored by a computerized feeding system. Animal Production 58, 145-152.

Zemmelink G (1980) Effect of Selective Feed Consumption on Voluntary Intake and Digestibility of Tropical Forages. Agricultural Research Report no. 896, Wageningen, The Netherlands: Pudoc.

Zemmelink G (1986) Measuring intake of tropical forages. In Recent Advances in Feed Evaluation and Rationing Systems for Dairy Cattle in Extensive and Intensive Production Systems. International Dairy Federation Bulletin no. 196, pp. 17-21 [CC Balch and AJH van Es, editors]. Brussels: International Dairy Federation. 